\title{
POLÍTICAS CULTURALES DEL ARCHIVO GENERAL DE LA NACIÓN
}

\section{Miguel Angel Vásquez Guillén \\ Universidad Católica Sedes Sapientiae \\ mvasquezg1981@gmail.com}

Fecha de recepción: agosto de 2014 Fecha de aceptación: octubre de 2014

Resumen: El presente trabajo plantea analizar las políticas culturales, objetivos estratégicos y actividades del Archivo General de la Nación. Al ser este un órgano ejecutor del Sector Cultura, tiene políticas culturales con las cuales gestiona el patrimonio documental de la nación. De igual manera, para el cumplimiento de estas actividades, el Estado le otorga un presupuesto anual.

* Miguel Angel Vásquez Guillén es licenciado en Historia por la Universidad Nacional Mayor de San Marcos. Ha realizado estudios de maestría en Gestión Cultural, Patrimonio y Turismo en la Universidad de San Martín de Porres. En el 2009 fue beneficiario por una Beca ENDESA para desarrollar una pasantía en la Subdirección de Archivos Estatales del ex Ministerio de Cultura de España. Sus temas de investigación se orientan a la gestión del patrimonio documental, realizando diversas publicaciones sobre el tema. Actualmente se desempeña como Responsable del Archivo Central del Programa Nacional de Apoyo Directo a los Más Pobres, JUNTOS. Asimismo, ejerce como docente a tiempo parcial en la Universidad Católica Sedes Sapientiae, además de participar como ponente en diversos eventos de capacitación. 
Las principales unidades de análisis escogidas serán los lineamientos de política del Archivo General de la Nación, por ser el ente rector del Sistema Nacional de Archivos y, como tal, su principal responsabilidad es conducir las políticas archivísticas en el país. Las fuentes primarias consultadas serán el Plan Estratégico Institucional 2012-2016, el Plan Operativo Institucional del año 2013, el informe de gestión del Plan operativo Institucional del año 2013 y la ejecución presupuestal del año 2013 del Archivo General de la Nación. De acuerdo al análisis de estas fuentes, serán reconocibles sus limitaciones operativas debido a razones presupuestales.

Palabras Clave: Políticas culturales, políticas públicas, archivística, gestión cultural.

\section{CULTURAL POLICIES OF GENERAL ARCHIVE OF THE NATION}

Aвstract: This work propose to analyze the cultural policies, strategic objectives and activities of the National Archive from Peru. As this is an executor of the Culture Sector organ, have a cultural policy which manages the documentary patrimony of the nation. Similarly, for the fulfillment of these activities, the State gives an annual budget Archives System their primary responsibility is to conduct archival policies in our country.

The principal units of analysis chosen will the policy guidelines of the General Archive of the Nation, as the governing body of the National Archives and as such, their main responsibility is to conduct archival policies in the country. The primary sources consulted are the Institutional Strategic Plan 2012-2016, the Institutional Operational Plan 2013, the management report of the Institutional Operational Plan 2013 and the budget execution in 2013 of the General Archive of the Nation. According to the analysis 
of these sources will be recognizable their operational limitations due to budgetary reasons.

KEYwords: Cultural policies, public policy, archival, cultural management.

\section{INTRODUCCIÓN}

7 Archivo General de la Nación es un organismo público adscrito al Ministerio de Cultura. Asimismo, es responsable de la protección del patrimonio documental de la nación. En este trabajo se analizan sus políticas culturales, derivadas para la protección del patrimonio cultural y su acceso a la sociedad.

De igual forma, para una mejor comprensión, se presentará una breve terminología archivística; una reseña del Archivo General de la Nación (en adelante nos referiremos a este como AGN) y resumiremos aquellos dispositivos legales que determinan sus competencias. Luego, analizaremos las políticas públicas contenidas en su Plan Estratégico Institucional para los años 2012 hasta el 2016. Cabe recalcar que de estas políticas públicas derivan las de índole cultural, las cuales motivan el presente trabajo.

\section{ARCHIVÍSTICA Y PATRIMONIO}

¿Qué es la archivística? La archivera española Antonia Heredia la define como «[la] Ciencia de los documentos de archivo y de los Archivos como custodios de aquellos y como sistemas responsables de su gestión, así como de la metodología aplicada a unos y a otros y cuyo objetivo es potenciar el 
uso y servicio de los documentos y de los Archivos" (Heredia 2011: 44). Esta definición será tomada en cuenta debido a la comprensión y sencillez manejada tanto para interesados y especialistas en el tema.

Se comprende por documentos de archivo aquellos que fueron generados, producidos, recibidos y conservados por una persona o institución. Además, contienen información relativa al ejercicio exclusivo de sus actividades y competencias, caracterizándose por «su naturalidad, su autenticidad, su integridad, su fiabilidad y su objetividad» (García 2012: 20). Asimismo, en su creación tienen una naturaleza estrictamente administrativa.

No todos los documentos de archivo son patrimonio. Obtienen este calificativo aquellos que presentan como característica su antigüedad, valor histórico, cultural, entre otros. Al respecto, encontramos un debate normativo de parte de nuestra legislación vigente. La postura se debate entre su definición específica ya sea como Patrimonio Documental o Patrimonio Cultural Archivístico. El primero está determinado por el Decreto Legislativo N. 19414, el mismo que precisa lo siguiente:

Está constituido por la documentación existente en los archivos de todas las reparticiones y organismos del Sector Público Nacional; en los archivos históricos, notariales, eclesiásticos, parroquiales y de conventos, en los archivos particulares y en general por el material documental, aun de origen privado, que sirvan de fuente de información para estudios históricos y del desarrollo cultural, social, económico, jurídico o religioso de la Nación. (AGN 1999: 17) 
Por su parte, el Patrimonio Cultural Archivístico está definido por el Decreto Supremo N. 011-2006-ED, con el cual se aprueba el reglamento de la ley general del Patrimonio Cultural de la Nación, definido como «el conjunto de documentos de cualquier época, manifestada en todas sus expresiones, en lenguaje natural y cualquier expresión gráfica, sonora o en imagen, recogidas tanto en soporte convencional o informático, generados y/o recibidos en cumplimiento de las competencias y actividades de las entidades públicas o privadas del ámbito nacional» (INC 2009: 50).

Pareciera que ambas definiciones son similares, pero difieren sobre su objeto de aplicación; todos aquellos documentos que sirven de fuente de investigación, conservados en los archivos, son Patrimonio Documental, y todos los documentos generados en cumplimiento de las funciones de una organización son Patrimonio Cultural Archivístico. En la primera, se refiere al valor histórico de los documentos, mientras la segunda se refiere a «todos» los documentos sin excepción. Aquello derivaría en una falacia, ya que no todos los documentos pueden ser reconocidos como Patrimonio Cultural, pues, de ser así, procuraríamos la conservación de todos los documentos que se generan tanto en el sector público como el privado.

Para que un documento se considere patrimonio cultural debe cumplir con ciertas características. Estas son las que siguen: (a) su importancia para la investigación, (b) el ser herencia de nuestros antepasados y (c) que su información sea significativa para la formación de nuestra identidad como sociedad. Ante esto, se infiere que la definición de Patrimonio Cultural Archivístico es incorrecta. Por ello, nos referiremos en las siguientes líneas al Patrimonio Documental de la Nación como el objeto de protección del AGN. De igual manera, no se utilizará la definición manejada por la 
UNESCO sobre Patrimonio Documental, debido a que en el presente análisis se utilizarán documentos normativos nacionales.

Para empezar a conocer las políticas culturales ejecutadas desde el Estado, habría que preguntarse antes ¿qué es una política pública? Para ello, Eugenio Lahera afirma lo siguiente: «Mientras la política es un concepto amplio, relativo al poder en general, las políticas públicas corresponden a soluciones específicas de cómo manejar los asuntos públicos» (Lahera 2004: 7). A partir de esto, podemos afirmar que las políticas públicas son el conjunto de normas, proyectos y acciones que promueve el Estado para solucionar determinados problemas de la sociedad.

En cuanto a políticas culturales, debido a que el AGN pertenece al sector Cultura, consideramos la definición aceptada por el Ministerio de Cultura. Desde su perspectiva, «Es un conjunto de orientaciones, normativas y proyectos que están destinados a democratizar la producción, la circulación y el consumo de objetos y servicios culturales. En ese sentido aspira a enriquecer la vida material y simbólica de una comunidad. Simultáneamente, contribuye al ejercicio de una ciudadanía plena» (Ministerio de Cultura 2012: 7). Esta posición oficial también será de apoyo en las páginas que siguen.

\section{EL ARCHIVO GENERAL DE LA NACIÓN}

El Archivo General de la Nación es un organismo público adscrito al Ministerio de Cultura. Su misión radica en «conducir y controlar el funcionamiento del Sistema Nacional de Archivos [que está] orientado a mejorar la conservación del Patrimonio Documental de la Nación a través de la modernización y capacitación archivística para optimizar los servicios 
archivísticos a la ciudadanía en general» (AGN s.f.: párr. 2). De igual forma, dicha misión se establece en conformidad con la legislación vigente.

El AGN tiene su antecedente en el Archivo Nacional, creada por el ex presidente Ramón Castilla en 1861 con el objetivo de «crear un archivo donde se depositen los documentos históricos y oficiales de la Región y de datos estadísticos de más importancia»(AGN 1999: 55). Finalizada la ocupación chilena de Lima, se decide reunir a la Biblioteca Nacional con el Archivo Nacional, formando una sola institución, hecho que se concretizó mediante un decreto del presidente Miguel Iglesias y cuya dirección asumirá Ricardo Palma. Esta situación se mantuvo hasta 1897, cuando el Archivo Nacional recupera su autonomía, nombrándose como director a Luis Benjamín Cisneros y encargándosele su reorganización. Sobre este acontecimiento, Guillermo Lohmann afirma «que recibió los fondos en las más absoluta confusión» (Lohmann 2000: 147).

El Archivo Nacional no sufre cambios hasta 1972, año en que también se promulga el decreto ley de creación del Instituto Nacional de Cultura. De esta forma, modifica su nombre por el de Archivo General de la Nación, convirtiéndose en un órgano ejecutor de la nueva institución (AGN 1972: 13); pero, al reactivarse el Ministerio de Justicia, el Archivo General de la Nación regresó a su nivel jerárquico, volviéndose un organismo público descentralizado, con autonomía administrativa y presupuestal (Cf. Cárdenas 1993). Finalmente, al crearse el Ministerio de Cultura en el 2010, el AGN deja de pertenecer al sector Justicia, para pertenecer al sector Cultura.

En cuando al aspecto jurídico, el AGN también se supedita a lo establecido por diferentes leyes. Los dispositivos legales que, vigentes a la fecha con rango de ley, brindan competencias al AGN son los siguientes: 
a) El Decreto Ley 19414: Ley de defensa, conservación e incremento del Patrimonio Documental de la Nación. Determina que todos aquellos documentos con más de 30 años de antigüedad deben transferirse al AGN. Asimismo, el AGN debe crear un registro de aquellas personas naturales o jurídicas que posean bienes integrantes del Patrimonio Documental de la Nación y está facultado para emitir normas que regulen los procesos archivísticos en los archivos del sector público nacional.

b) La Ley 25323: Ley que crea el Sistema Nacional de Archivos, reconoce al AGN como órgano rector del Sistema Nacional de Archivos, el cual está conformado por los archivos regionales y los archivos públicos, legislando su capacitad de emitir normas archivísticas nacionales.

c) La Ley 28296: Ley general del Patrimonio Cultural de la Nación, reconoce al AGN como el encargado de identificación, inventario, inscripción, registro, investigación, protección, conservación, difusión y promoción del Patrimonio Documental de la Nación. ${ }^{1}$ Además le otorga capacidad sancionadora contra aquellos que incumplan con el registro, dañen o saquen fuera del país algún bien integrante del Patrimonio Documental de la Nación. Dispone, además, la creación del Registro Nacional de Colecciones Documentales y de Archivos Históricos Públicos o de Particulares.

1 Este dispositivo legal lo define como Patrimonio Cultural Archivístico, lo cual es incorrecto según se explicaron líneas arriba. 
Por otro lado, el Reglamento de Organización y Funciones (ROF) influencia también en las actividades del AGN. Este determina que las funciones del Archivo son las siguientes:

a) Establecer los lineamientos de política nacional en materia de archivos.

b) Impulsar el desarrollo del Sistema Nacional de Archivos.

c) Formular y emitir normas técnicas sobre organización y funcionamiento de los archivos integrantes del Sistema Nacional de Archivos.

d) Asesorar, supervisar y evaluar el funcionamiento de los archivos integrantes del Sistema Nacional de Archivos.

e) Normar sobre la producción y administración de los documentos de los archivos públicos a nivel nacional.

f) Calificar, defender, conservar, organizar, describir, seleccionar y servir el Patrimonio Documental de la Nación que custodia así como recepcionar la transferencia de la documentación proveniente del Sector Público Nacional y Notarías, con sujeción a la legislación sobre la materia.

g) Garantizar la puesta en servicio del Patrimonio Documental de la Nación, con excepción de los documentos cuya naturaleza comprometen la seguridad nacional.

h) Promover, apoyar y realizar la formación profesional y capacitación especializada en archivística.

i) Velar por el cumplimiento de las normas legales en materia de archivos y documentos.

j) Realizar y fomentar la investigación archivística. 
k) Registrar, inspeccionar y supervisar los archivos privados que se adhieren al Sistema y que custodien documentos de valor histórico.

1) Calificar y autorizar la aplicación de la tecnología moderna en los archivos integrantes del Sistema Nacional de Archivos.

m) Imponer sanciones a las personas naturales o jurídicas que contravengan las normas que protegen el Patrimonio Documental de la Nación.

n) Ejercer el derecho de preferencia en la adquisición de documentos de interés y el derecho de retracto en casos de transferencia.

n) Las demás que le corresponde de acuerdo a ley. (AGN 1999: 6162)

De acuerdo a las estipulaciones señaladas, podemos resumir las atribuciones del AGN en la siguiente relación: (a) Normar en materia archivística; (b) asesorar y supervisar el funcionamiento de los archivos públicos; (c) gestionar el Patrimonio Documental que conserva; (d) elaborar normas que protejan al Patrimonio Documental y (e) promover la capacitación y formación archivística. Estas ideas también serán manejadas a lo largo del texto.

\section{LAS POLÍTICAS PÚBLICAS Y CULTURALES DEL AGN}

Como mencionamos anteriormente, las políticas públicas son el conjunto de acciones, normas y proyectos destinados a solucionar problemas específicos de la sociedad. El AGN, para los años 2012 al 2016, plantea sus políticas en los siguientes lineamientos: (a) la organización y conservación documental; (b) el fortalecimiento del Sistema Nacional de archivos y la formación y (c) 
capacitación archivística. Cada lineamiento contiene, a su vez, sus propias políticas. Estas serán presentadas en la siguiente tabla:

Tabla 1

Lineamientos y politicas del $A G N$

\begin{tabular}{|l|l|}
\hline \multicolumn{1}{|c|}{ LINEAMIENTOS } & \multicolumn{1}{c|}{ POLÍTICAS } \\
\hline \multirow{2}{*}{$\begin{array}{l}\text { ORGANIZACIÓN Y } \\
\text { CONSERVACIÓN DO- } \\
\text { CUMENTAL }\end{array}$} & $\begin{array}{l}\text { Intensificar los procesos archivísticos de la organi- } \\
\text { zación y niveles de descripción y homogenizar los } \\
\text { mismos. }\end{array}$ \\
\cline { 2 - 2 } $\begin{array}{l}\text { Desarrollar un plan integral de conservación pre- } \\
\text { ventiva y restauración del Patrimonio Documental } \\
\text { de la Nación. }\end{array}$ \\
\hline \multirow{2}{*}{$\begin{array}{l}\text { FERTALECIMIENTO SISTEMA NACIO- } \\
\text { NAL DE ARCHIVOS }\end{array}$} & $\begin{array}{l}\text { Coadyuvar al fortalecimiento y desarrollo del Sis- } \\
\text { tema Nacional de Archivos. }\end{array}$ \\
\cline { 2 - 2 } & Actualizar el marco normativo archivístico. \\
\hline \multirow{2}{*}{$\begin{array}{l}\text { FORMACIÓN Y CAPA- } \\
\text { CITACIÓN ARCHIVÍS- } \\
\text { TICA }\end{array}$} & $\begin{array}{l}\text { Ampliar oportunidades de la formación profesio- } \\
\text { nal del archivero y desarrollo del programa de ca- } \\
\text { pacitación continua a nivel nacional. }\end{array}$ \\
\cline { 2 - 2 } & $\begin{array}{l}\text { Liderar la formación profesional y capacitación en } \\
\text { materia archivística. }\end{array}$ \\
\cline { 2 - 3 } & $\begin{array}{l}\text { Proponer la extensión universitaria de la carrera } \\
\text { archivística. }\end{array}$ \\
\hline
\end{tabular}

Nota: Plan estratégico institucional. 2012-2016. Lima: Archivo General de la Nación, 2013, p. 17. 
Bajo estos tres lineamientos en su política, el AGN ejecuta y/o formula documentos normativos, actividades de difusión, cursos de formación, entre otros. De estas políticas, la política cultural es la primera por referirse a la organización y conservación del Patrimonio Documental. Asimismo, de esta deriva un objetivo general con sus respectivos objetivos específicos. A continuación, mostramos dichos objetivos en la presente tabla:

Tabla 2

Objetivo general y objetivos especificos de la politica cultural del AGN

\begin{tabular}{|c|c|}
\hline OBJETIVO GENERAL & OBJETIVOS ESPECÍFICOS \\
\hline \multirow{4}{*}{$\begin{array}{l}\text { Impulsar la organización, } \\
\text { descripción y conservación } \\
\text { preventiva del Patrimonio } \\
\text { Documental de la Nación } \\
\text { que custodia el AGN, para } \\
\text { ampliar la difusión y servicios } \\
\text { archivísticos. }\end{array}$} & $\begin{array}{l}\text { Dinamizar la organización y descripción de los } \\
\text { fondos y colecciones documentales para brindar } \\
\text { un mejor servicio a la comunidad. }\end{array}$ \\
\hline & $\begin{array}{l}\text { Digitalizar en forma gradual los fondos y co- } \\
\text { lecciones documentales que custodia la entidad } \\
\text { como un medio de preservación y seguridad. }\end{array}$ \\
\hline & $\begin{array}{l}\text { Recuperar la integridad física y funcional de los } \\
\text { documentos deteriorados a través de la restau- } \\
\text { ración. }\end{array}$ \\
\hline & $\begin{array}{l}\text { Desarrollar el programa de conservación preven- } \\
\text { tiva de los fondos y colecciones documentales. }\end{array}$ \\
\hline
\end{tabular}

Nota: Plan estratégico institucional. 2012-2016. Lima: Archivo General de la Nación, 2013, p. 18. 
A partir de lo dicho, se evidencia que las políticas culturales del AGN tienen como universo el patrimonio documental que custodia, competencia que tiene según su Reglamento de Organización y Funciones. Pero, como se mencionó previamente, el AGN también tiene otras atribuciones que fueran determinadas por mandato legal como la difusión, promoción, inventario, registro del Patrimonio Documental y de sus propietarios. Por lo tanto, su universo debe contemplar al que se conserva en el territorio nacional, por lo cual llama la atención que estas acciones no se contemplen en su Plan Estratégico Institucional de los años 2012 al 2016 y el Plan Operativo Institucional 2013 (Cf. AGN 2013b).

El segundo lineamiento puede considerarse como política cultural, pero solo parcialmente, porque está destinada principalmente a brindar apoyo a los integrantes del Sistema Nacional de Archivos, con asesoramiento y capacitación para gestionar los documentos que conservan, de los cuales no todos son patrimonio documental. Cabe señalar que este segundo lineamiento mantiene relación directa con los archivos del Sistema. Asimismo, se presenta su objetivo general y objetivos específicos en la siguiente tabla: 
Tabla 3

Objetivo general y objetivos específicos del segundo lineamiento en la politica cultural del $A G N$

\begin{tabular}{|c|c|}
\hline OBJETIVO GENERAL & OBJETIVOS ESPECÍFICOS \\
\hline \multirow{4}{*}{$\begin{array}{l}\text { Reforzar el desarrollo del Sis- } \\
\text { tema Nacional de Archivos, } \\
\text { a través de la actualización } \\
\text { de la normatividad archivís- } \\
\text { tica, las reuniones técnicas } \\
\text { y asesoramientos en materia } \\
\text { archivística a nivel nacional } \\
\text { involucrando a los archivos } \\
\text { del Sector Público y Privado. }\end{array}$} & $\begin{array}{l}\text { Apoyar el funcionamiento de los archivos que } \\
\text { conforman el Sistema Nacional de Archivos, } \\
\text { mediante acciones de supervisión, asesoramiento } \\
\text { y charlas de orientación archivística, a fin de } \\
\text { mejorar la organización y administración de } \\
\text { archivos. }\end{array}$ \\
\hline & $\begin{array}{l}\text { Realizar reuniones técnicas donde se analicen los } \\
\text { problemas comunes, uniformicen los criterios } \\
\text { técnicos archivísticos a nivel nacional. }\end{array}$ \\
\hline & $\begin{array}{l}\text { Lograr el apoyo de las autoridades nacionales y } \\
\text { regionales para asignar mayores recursos a los } \\
\text { archivos públicos y archivos regionales. }\end{array}$ \\
\hline & $\begin{array}{l}\text { Actualizar el marco normativo técnico - } \\
\text { administrativo a fin de mejorar el funcionamiento } \\
\text { de los archivos que conforman el Sistema } \\
\text { Nacional de Archivos. }\end{array}$ \\
\hline
\end{tabular}

Nota: Plan estratégico institucional. 2012-2016. Lima: Archivo General de la Nación, 2013, pp. 18-19. 
Es en este segundo objetivo general donde amplía su universo a los integrantes del Sistema Nacional de Archivos. Sin embargo, se realiza a través de reuniones técnicas, supervisiones, asesoramiento y charlas de orientación. Es decir, actúa de forma indirecta para la gestión del patrimonio documental, mientras que los actores directos son los archivos que lo conservan.

Asimismo, tampoco se considera la recuperación del patrimonio documental que fuera sustraído del AGN. El tráfico ilícito de estos bienes es una realidad denunciada en diversas oportunidades por sus funcionarios a través de los medios de prensa (Cf. Salazar 2012). En un desgraciado contraste, podemos encontrar, incluso vía internet, avisos donde se ofrecen documentos históricos peruanos (Cf. El Comercio 2010).

Por otro lado, se considera como una de las causas por las cuales el AGN no tiene políticas culturales que afecten directamente a la protección y recuperación del patrimonio documental en el territorio nacional a su presupuesto. Para el año 2013, el AGN tuvo un presupuesto institucional de apertura de $S / 9,431,919$; el mismo que durante ese año fuera elevado a S/. 9, 823,326 nuevos soles en comparación con el presupuesto destinado a la Biblioteca Nacional del Perú. Esta tuvo una apertura de S/. 21, 884,600, modificándose después a S/. 29, 420,373. A continuación, se mostrará la relación de dichas cifras en la siguiente tabla: 
Tabla 4

Presupuestos institucionales de apertura y modificado para el $A G N$ y BNP en el 2013

\begin{tabular}{|c|c|c|}
\hline \multicolumn{3}{|c|}{ PRESUPUESTO 2013 } \\
\hline INSTITUCIÓN & $\begin{array}{c}\text { PRESUPUESTO } \\
\text { INSTITUCIONAL } \\
\text { DE APERTURA } \\
\text { (PIA) }\end{array}$ & $\begin{array}{c}\text { PRESUPUESTO } \\
\text { INSTITUCIONAL } \\
\text { MODIFICADO } \\
\text { (PIM) }\end{array}$ \\
\hline $\begin{array}{c}\text { ARCHIVO GENERAL DE LA } \\
\text { NACIÓN }\end{array}$ & $9,431,919$ & $9,823,326$ \\
\hline $\begin{array}{c}\text { BIBLIOTECA NACIONAL } \\
\text { DEL PERÚ }\end{array}$ & $21,884,600$ & $29,420,373$ \\
\hline DIFERENCIA & $12,52,681$ & $19,597,047$ \\
\hline
\end{tabular}

Nota: «Portal de Transparencia Económica». <http://www.mef.gob.pe/index. php?option=com_content $\&$ view=article $\&$ id $=504$ :seguimiento-de-la-ejecucion-presupuestal-diaria\&catid=267: seguimiento-de-la-ejecucion-presupuestal-diaria\&Itemid=100944>. Ministerio de Economía y Finanzas. Consulta hecha en 17/08/ 2014.

De acuerdo a los datos presentados, el presupuesto institucional de la Biblioteca Nacional del Perú supera el 300\% al destinado y utilizado por el AGN. Esto puede deberse a que los archivos no son considerados como fuente de recursos económicos y culturales en nuestro país, según lo da a entender el estudio presentado por el Instituto de Investigación de la Escuela de Turismo y Hotelería de la Universidad de San Martín de Porres en el año 
2005. En este se analizan, además, diversos aportes de industrias culturales, incluyendo los museos, a la economía nacional (Cf. IIETHUSMP 2005). Sin embargo, no reconoce la participación de los archivos, aún cunando también tienen un impacto en la economía nacional, pues los servicios que ofrecen derivan en ingresos económicos. Cabe señalar que estos casi 10 millones de nuevos soles de presupuesto del AGN, deben distribuirse en pagos de servicios básicos (telefonía, electricidad, agua y desagüe); pago de remuneraciones; obligaciones previsionales; adquisición de útiles de oficina, arbitrios, entre otros. Por ello, el presupuesto resulta insuficiente para desarrollar actividades directas en el ámbito nacional.

\section{TAREAS Y ACTIVIDADES DERIVADAS}

De la política cultural del AGN derivan una serie de actividades, destinadas a cumplir objetivos institucionales. Estas actividades pueden dividirse en cuatro tareas. Estas vendrían a ser las que siguen: conservación, digitalización, organización y descripción de documentos. A continuación, se muestra la relación de dichas actividades en la siguiente tabla: 
Tabla 5

Actividades derivadas de la política cultural del AGN

\begin{tabular}{|c|c|c|c|c|}
\hline TAREA & $\begin{array}{l}\text { DIREC- } \\
\text { CIÓN EN- } \\
\text { CARGADA }\end{array}$ & ACTIVIDAD & $\begin{array}{l}\text { UNIDAD DE } \\
\text { MEDIDA }\end{array}$ & $\begin{array}{l}\text { META } \\
\text { LOGRA- } \\
\text { DA }\end{array}$ \\
\hline \multirow{6}{*}{$\begin{array}{l}\text { CONSER- } \\
\text { VACIÓN } \\
\text { DE DOCU- } \\
\text { MENTOS }\end{array}$} & \multirow{6}{*}{$\begin{array}{l}\text { Dirección de } \\
\text { Conserva- } \\
\text { ción }\end{array}$} & $\begin{array}{l}\text { Restauración de } \\
\text { documentos }\end{array}$ & Hojas & 4,727 \\
\hline & & $\begin{array}{l}\text { Encuadernación } \\
\text { de documentos }\end{array}$ & Unidad & 190 \\
\hline & & $\begin{array}{l}\text { Impresión de for- } \\
\text { matos }\end{array}$ & Copias & 55,759 \\
\hline & & $\begin{array}{l}\text { Preservación de } \\
\text { documentos }\end{array}$ & Metros lineales & 19,376 \\
\hline & & $\begin{array}{l}\text { Asesoramiento en } \\
\text { conservación }\end{array}$ & Informe & 12 \\
\hline & & $\begin{array}{l}\text { Fotocopia de do- } \\
\text { cumentos }\end{array}$ & Copias & 121,129 \\
\hline $\begin{array}{l}\text { DIGITALI- } \\
\text { ZACIÓN } \\
\text { DE LOS } \\
\text { FONDOS } \\
\text { DOCU- } \\
\text { MENTALES }\end{array}$ & $\begin{array}{l}\text { Dirección } \\
\text { de Con- } \\
\text { servación / } \\
\text { Dirección } \\
\text { de Archivos } \\
\text { Públicos }\end{array}$ & Digitalización & Imagen & 496,190 \\
\hline
\end{tabular}




\begin{tabular}{|c|c|c|c|c|}
\hline TAREA & $\begin{array}{l}\text { DIREC- } \\
\text { CIÓN EN- } \\
\text { CARGADA }\end{array}$ & ACTIVIDAD & $\begin{array}{l}\text { UNIDAD DE } \\
\text { MEDIDA }\end{array}$ & $\begin{array}{l}\text { META } \\
\text { LOGRA- } \\
\text { DA }\end{array}$ \\
\hline \multirow{7}{*}{$\begin{array}{l}\text { DESCRIP- } \\
\text { CIÓN DE } \\
\text { FONDOS } \\
\text { DOCU- } \\
\text { MENTALES }\end{array}$} & \multirow{5}{*}{$\begin{array}{l}\text { Dirección } \\
\text { de Archivo } \\
\text { Republicano }\end{array}$} & $\begin{array}{l}\text { Inventario de RPJ } \\
\text { Causas Civiles }\end{array}$ & Registros & 1425 \\
\hline & & $\begin{array}{l}\text { Inventario de la } \\
\text { serie Asuntos In- } \\
\text { dígenas }\end{array}$ & Registros & 3,936 \\
\hline & & $\begin{array}{l}\text { Inventario de las } \\
\text { cartas oficiales del } \\
\text { Ministerio de Ha- } \\
\text { cienda OL - H1 }\end{array}$ & Registros & 16,359 \\
\hline & & Autógrafas de ley & Registros & 1,162 \\
\hline & & $\begin{array}{l}\text { Archivo agrario } \\
\text { - Hacienda Casa } \\
\text { Grande }\end{array}$ & Metros lineales & 65 \\
\hline & \multirow{2}{*}{$\begin{array}{l}\text { Archivos } \\
\text { Públicos }\end{array}$} & $\begin{array}{l}\text { Digitación de } \\
\text { Registros Civiles }\end{array}$ & $\begin{array}{l}\text { Pieza docu- } \\
\text { mental }\end{array}$ & 0 \\
\hline & & $\begin{array}{l}\text { Indizado de actas } \\
\text { de RRCC }\end{array}$ & $\begin{array}{l}\text { Pieza docu- } \\
\text { mental }\end{array}$ & 0 \\
\hline $\begin{array}{l}\text { DESCRIP- } \\
\text { CIÓN DE } \\
\text { FONDOS } \\
\text { DOCU- } \\
\text { MENTALES }\end{array}$ & $\begin{array}{l}\text { Archivos } \\
\text { Notariales y } \\
\text { Judiciales }\end{array}$ & $\begin{array}{l}\text { Inventario de los } \\
\text { Archivos Judiciales }\end{array}$ & Metros lineales & 0 \\
\hline
\end{tabular}




\begin{tabular}{|c|c|c|c|c|}
\hline TAREA & $\begin{array}{l}\text { DIREC- } \\
\text { CIÓN EN- } \\
\text { CARGADA }\end{array}$ & ACTIVIDAD & $\begin{array}{l}\text { UNIDAD DE } \\
\text { MEDIDA }\end{array}$ & $\begin{array}{l}\text { META } \\
\text { LOGRA- } \\
\text { DA }\end{array}$ \\
\hline \multirow{9}{*}{$\begin{array}{l}\text { ORGANI- } \\
\text { ZACIÓN } \\
\text { DE DOCU- } \\
\text { MENTOS }\end{array}$} & \multirow{3}{*}{$\begin{array}{l}\text { Archivo } \\
\text { Colonial }\end{array}$} & $\begin{array}{l}\text { Organización de } \\
\text { Real Hacienda }\end{array}$ & Metros lineales & 11,20 \\
\hline & & $\begin{array}{l}\text { Organización del } \\
\text { fondo Tribunal de } \\
\text { la Inquisición de } \\
\text { Lima }\end{array}$ & Metros lineales & 19,8 \\
\hline & & $\begin{array}{l}\text { Organización del } \\
\text { fondo Real Tribu- } \\
\text { nal de Minería }\end{array}$ & Metros lineales & 6,125 \\
\hline & $\begin{array}{l}\text { Archivo Re- } \\
\text { publicano }\end{array}$ & $\begin{array}{l}\text { Organización del } \\
\text { Archivo Agrario } \\
\text { - Hacienda Mon- } \\
\text { talván }\end{array}$ & Metros lineales & 45 \\
\hline & $\begin{array}{l}\text { Archivo Re- } \\
\text { publicano }\end{array}$ & $\begin{array}{l}\text { Organización del } \\
\text { Archivo Agrario } \\
\text { - Hacienda Casa } \\
\text { Grande } \\
\end{array}$ & Metros lineales & 65,4 \\
\hline & \multirow{3}{*}{$\begin{array}{l}\text { Archivos } \\
\text { Públicos }\end{array}$} & $\begin{array}{l}\text { Organización de } \\
\text { fondos }\end{array}$ & Metros lineales & 308,97 \\
\hline & & Valoración & Metros lineales & 452,65 \\
\hline & & Eliminación & Metros lineales & 398,85 \\
\hline & $\begin{array}{l}\text { Archivos } \\
\text { Notariales y } \\
\text { Judiciales }\end{array}$ & $\begin{array}{l}\text { Organización de } \\
\text { los Archivos Judi- } \\
\text { ciales }\end{array}$ & Metros lineales & 0 \\
\hline
\end{tabular}




\begin{tabular}{|c|c|c|c|c|}
\hline TAREA & $\begin{array}{l}\text { DIREC- } \\
\text { CIÓN EN- } \\
\text { CARGADA }\end{array}$ & ACTIVIDAD & $\begin{array}{l}\text { UNIDAD DE } \\
\text { MEDIDA }\end{array}$ & $\begin{array}{l}\text { META } \\
\text { LOGRA- } \\
\text { DA }\end{array}$ \\
\hline \multirow{2}{*}{$\begin{array}{l}\text { DESCRIP- } \\
\text { CIÓN DE } \\
\text { FONDOS } \\
\text { DOCU- } \\
\text { MENTALES }\end{array}$} & \multirow[t]{2}{*}{$\begin{array}{l}\text { Archivo } \\
\text { Colonial }\end{array}$} & $\begin{array}{l}\text { Inventario to- } \\
\text { pográfico de los } \\
\text { fondos documen- } \\
\text { tales del Archivo } \\
\text { Colonial }\end{array}$ & Metros lineales & 1,881 \\
\hline & & $\begin{array}{l}\text { Inventario de Real } \\
\text { Hacienda }\end{array}$ & $\begin{array}{l}\text { Pieza docu- } \\
\text { mental }\end{array}$ & 7,900 \\
\hline \multirow{4}{*}{$\begin{array}{l}\text { DESCRIP- } \\
\text { CIÓN DE } \\
\text { FONDOS } \\
\text { DOCU- } \\
\text { MENTALES }\end{array}$} & \multirow{4}{*}{$\begin{array}{l}\text { Archivo } \\
\text { Colonial }\end{array}$} & $\begin{array}{l}\text { Inventario del fon- } \\
\text { do Real Tribunal } \\
\text { de la Inquisición } \\
\text { de Lima }\end{array}$ & $\begin{array}{l}\text { Pieza docu- } \\
\text { mental }\end{array}$ & 4,378 \\
\hline & & $\begin{array}{l}\text { Digitación de } \\
\text { fichas descriptivas }\end{array}$ & $\begin{array}{c}\text { Fichas descrip- } \\
\text { tivas }\end{array}$ & 10,934 \\
\hline & & $\begin{array}{l}\text { Inventario del } \\
\text { fondo Real Mi- } \\
\text { nería }\end{array}$ & $\begin{array}{l}\text { Pieza docu- } \\
\text { mental }\end{array}$ & 2,373 \\
\hline & & $\begin{array}{l}\text { Digitación de } \\
\text { fichas descriptivas } \\
\text { del Proyecto de } \\
\text { Informatización }\end{array}$ & Fichas & 10,934 \\
\hline
\end{tabular}

Nota: Evaluación del Plan Operativo Institucional 2013. Lima: Archivo General de la Nación, 2014, pp. 6-8. 
Debe recordarse que uno de los objetivos de la archivística es potenciar el uso y servicio de los documentos. Por ello, las actividades descritas tienen como objetivo final el servicio del patrimonio documental que conserva el AGN a sus usuarios. Ahora bien, se lleva un registro de los servicios brindados por el AGN durante el año 2013. Dicha relación se presentará en la siguiente tabla:

Tabla 6

Servicios brindados por el AGN durante el 2013

\begin{tabular}{|c|c|c|c|}
\hline $\begin{array}{l}\text { DIRECCIÓN EN- } \\
\text { CARGADA }\end{array}$ & $\begin{array}{c}\text { TIPOS DE SER- } \\
\text { VICIO }\end{array}$ & $\begin{array}{c}\text { CANTIDAD } \\
\text { DE SERVICIOS } \\
\text { BRINDADOS }\end{array}$ & TOTAL \\
\hline \multirow{2}{*}{$\begin{array}{l}\text { DIRECCIÓN NA- } \\
\text { CIONAL DE ARCHI- } \\
\text { VO HISTÓRICO }\end{array}$} & Investigadores & 3,179 & 3,179 \\
\hline & $\begin{array}{l}\text { Usuarios particu- } \\
\text { lares }\end{array}$ & 2,118 & 2,118 \\
\hline $\begin{array}{l}\text { DIRECCIÓN ARCHI- } \\
\text { VOS NOTARIALES Y } \\
\text { JUDICIALES }\end{array}$ & $\begin{array}{l}\text { Expediciones de } \\
\text { copias notariales }\end{array}$ & 3,367 & 3,367 \\
\hline \multirow{3}{*}{$\begin{array}{l}\text { DIRECCIÓN DE AR- } \\
\text { CHIVOS PÚBLICOS }\end{array}$} & Copias certificadas & 1,404 & \multirow{3}{*}{3,311} \\
\hline & Constancias & 476 & \\
\hline & $\begin{array}{l}\text { Búsqueda de docu- } \\
\text { mentos }\end{array}$ & 1,431 & \\
\hline \multirow{2}{*}{$\begin{array}{l}\text { DIRECCIÓN DE AR- } \\
\text { CHIVOS PÚBLICOS }\end{array}$} & Atención en sala & 350 & \multirow{2}{*}{1,523} \\
\hline & Consultas & 1,173 & \\
\hline
\end{tabular}

Nota: Evaluación del Plan Operativo Institucional 2013. Lima: Archivo General de la Nación, 2014, pp. 15-16. 
Por otra parte, durante aquel año, el AGN brindó 13,498 servicios a investigadores y usuarios. De igual manera, lograron generar ingresos monetarios. Por ello, la gestión de archivos también puede considerarse como una actividad económica.

\section{CONCLUSIONES}

A modo de conclusión, podemos afirmar que el Plan Estratégico Institucional del AGN contiene determinadas políticas culturales, las cuales se limitan a la gestión del patrimonio documental que conserva. A su vez, esta gestión se deriva en atender las necesidades de sus usuarios. De igual forma, no se olvide que el AGN pone a disposición el patrimonio documental que conserva a usuarios particulares e investigadores.

Asimismo, es claro que, al tener como universo al patrimonio documental que conserva, deje de cumplir otros objetivos que les son atribuidos según la legislación vigente. Por ejemplo, se obvia el registro nacional del patrimonio documental y de sus poseedores. Esto se debe al presupuesto institucional manejado, el cual es inferior en comparación con el destinado a la Biblioteca Nacional del Perú, ya que la gestión de archivos no es considerada como una actividad económica.

A la fecha, el AGN ha incrementado sus actividades de difusión a través de la publicación de su revista institucional. Igualmente, ha asumido la organización de conferencias, gestión de visitas guiadas, desarrollo de reuniones técnicas y uso de las redes sociales. Ha demostrado, a su vez, una apertura a desarrollar actividades en coordinación con otras instituciones. A continuación, se muestra una relación de ellas: 
a) Desarrollo de visitas guiadas en las que puede gestionar convenios de cooperación con universidades que cuenten con escuelas de turismo, buscando que los estudiantes puedan realizar prácticas y ser ellos quienes dirijan estas visitas o apoyen en su mejora.

b) Gestión de convenios con instituciones que cuenten con archivos históricos ubicados en el Centro Histórico de Lima, para desarrollar actividades paralelas con motivo de alguna celebración nacional como la Independencia, la fundación de Lima, el combate de Angamos, entre otros, aprovechando para ello la ubicación turística (ver Figura 1).

Finalmente, los servicios que derivan de la gestión del patrimonio documental deben considerarse como actividad económica, la misma que genera recursos para el AGN. Esto debe tomarse en cuenta para incrementar su presupuesto institucional y nivelarlo, al menos, con el de la Biblioteca Nacional del Perú. Dicha implementación, daría pie a una mayor cantidad de posibilidades de gestión y desarrollo de esta institución decididamente emblemática en el país. 


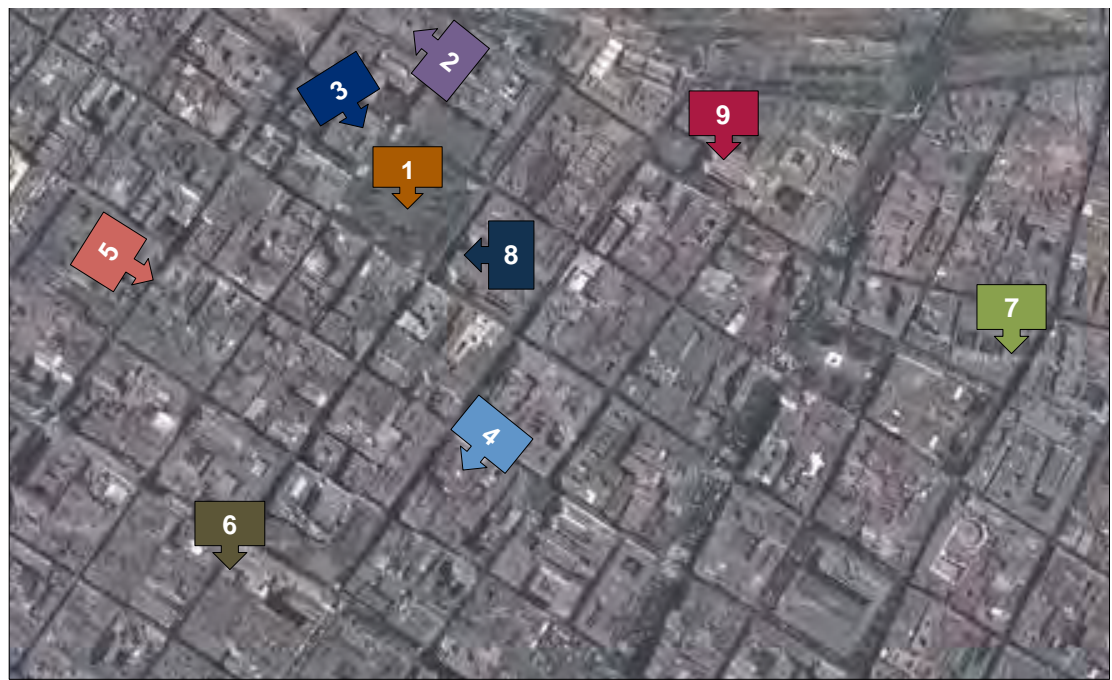

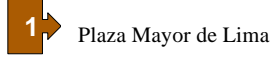

Archivo Colonial - Archivo
General de la Nación

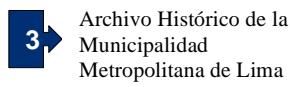

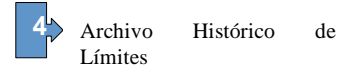

Límites

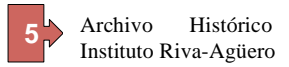

del
6. Archivo Histórico de la Sociedad de Beneficencia de Lima

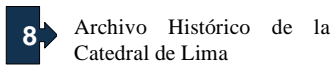

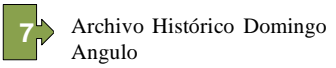

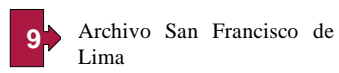

Figura 1. Ubicación de archivos históricos en Cercado de Lima. Tomado de Vásquez Guillén 2014: 198. 


\section{REFERENCIAS}

Archivo General de la Nación

1972 «Sección oficial». Revista del Archivo General de la Nación. N. 1, pp. 9-24.

1999 Legislación archivistica peruana. 2. ${ }^{a}$ ed. Lima: Archivo General de la Nación.

2013a Plan estratégico institucional. 2012-2016. Lima: Archivo General de la Nación.

2013b Plan operativo institucional. 2012. Lima: Archivo General de la Nación.

2014 Evaluación del Plan Operativo Institucional 2013. Lima: Archivo General de la Nación.

"Archivo General de la Nación». En Archivo General de la
Nación. <http://www.agn.gob.pe/objetivos-generales.html>.
Consulta hecha en 02/07/2014.
dGuillermo Durand Flórez: Semblanza de un archivero». Revista
del Archivo General de la Nación, N. 10, pp. 13-24. 
El Comercio

2010 «Unas diez personas son investigadas en el Poder Judicial por tráfico de patrimonio documental». El Comercio, diario de Perú, 30 de octubre. <http://elcomercio.pe/lima/662009/ noticia-unas-diez-personas-son-investigadas-poder-judicialtrafico-patrimonio-documental>. Consula hecha en 17/04/2013.

GARCíA RuiPÉREZ, Mariano

2012 Archivistica: Documentos y archivos. Principios y funciones. Ingresos y salidas de documentos. Los sistemas de archivos. Toledo: UNIA.

Heredia Herrera, Antonia

2011 Lenguaje y vocabulario archivisticos, algo más que un diccionario. Andalucía: Junta de Andalucía, Consejería de Cultura.

Instituto de InVestigación de la Escuela de Turismo y Hotelería de la Universidad de San Martín de Porres 2005 El impacto económico de la cultura en Perú. Bogotá: Convenio Andrés Bello.

Instituto Nacional de Cultura

2009 Marco legal de protección del patrimonio. Lima: Instituto Nacional de Cultura. 
LAHERA, Eugenio

2004 Politica y políticas públicas. Santiago de Chile: Naciones Unidas - CEPAL.

LOHMANN ViLLENA, Guillermo

2000 «Los fondos del Archivo General de la Nación y su valor para la investigación». Revista del Archivo General de la Nación, N. 21, pp. 137-156.

\section{Ministerio de Cultura}

2012

Lineamientos de politica cultural 2013-2016. Versión preliminar. Lima: Ministerio de Cultura.

Ministerio de Economía y Finanzas

s.f. «Portal de Transparencia Económica». <http://apps5. mineco.gob.pe/transparencia/Navegador/default. aspx?y=2013\&ap=ActProy>. Ministerio de Economía y Finanzas. Consulta hecha en 17/08/2014.

Salazar Vega, Elizabeth

2012 «Archivo General de la Nación tampoco se salvó del hurto de documentos». <http://elcomercio.pe/lima/1261679/noticiarobo-bnp-archivo-general-nacion-tampoco-se-salvo-hurto- 
documentos>. El Comercio.pe. 30/08/2012. Consulta hecha en $28 / 08 / 2013$.

VÁSQUez GuilléN, Miguel

2014 «Relaciones entre el patrimonio documental y el turismo: Una mirada latinoamericana». En SAnabria, Daniel. El patrimonio documental cultural: De la teoría a la acción. Cáceres: Fundación Ciencias de la Documentación, pp. 189-210. 